\title{
Breast Nodular Fasciitis: A Comprehensive Review
}

\author{
Panagiotis Paliogiannis $^{a} \quad$ Antonio Cossu $^{b} \quad$ Giuseppe Palmieri $^{c}$ Fabrizio Scognamillo $^{a}$ \\ Carlo Pala $^{a}$ Rita Nonnis ${ }^{a}$ Giovanni Sotgiu $^{d}$ Alessandro Fois $^{e}$ Grazia Palomba $^{c}$ \\ Federico Attene ${ }^{a}$
}

\author{
a O.U. of Surgery I (Surgical Pathology), A.O.U. Sassari, Sassari, Italy; \\ ${ }^{b}$ O.U. of Pathology, A.O.U. Sassari, Sassari, Italy; \\ ${ }^{\mathrm{c}}$ Institute of Biomolecular Chemistry, Cancer Genetics Unit, C.N.R., Sassari, Italy; \\ ${ }^{d}$ Epidemiology and Medical Statistics Unit, Department of Biomedical Sciences, University of Sassari - Research, \\ Medical Education and Professional Development Unit, A.O.U. Sassari, Sassari, Italy; \\ ${ }^{e}$ Department of Clinical and Experimental Medicine, University of Sassari, Sassari, Italy
}

\section{Keywords}

Nodular fasciitis - Pseudosarcomatous .

Pseudoneoplastic

\section{Summary}

Background: This article describes the demographic, clinical, pathological and prognostic features of breast nodular fasciitis through a comprehensive review of the cases reported in modern literature. Material and Methods: English-language articles published from January 1970 to October 2015 and related to breast nodular fasciitis were non-systematically retrieved using the PubMed database. Titles, abstracts and references were evaluated in order to include the most relevant studies. The demographic characteristics of the patients and the signs and symptoms of the disease were reviewed, as well as the results of the radiological and diagnostic procedures employed and of the treatments adopted. Results: 26 papers reporting on 28 cases were enrolled; however, manuscripts published before 1990 were excluded because of old methodologies, technologies and clinical approaches. Thus, 22 cases included in 20 papers were analyzed in detail. Conclusion: The rarity and the unspecific clinical and radiological characteristics of breast nodular fasciitis make the differential diagnosis and management challenging. Knowledge of the clinical, pathological and prognostic aspects of this condition is crucial for breast care specialists in order to improve their diagnostic and therapeutic interventions.

(c) 2016 S. Karger GmbH, Freiburg

P.P. and A.C. contributed equally to this work.

\section{Introduction}

Nodular fasciitis, described for the first time in 1955 by Konwaler et al. [1], is a benign disorder characterized by a pseudoneoplastic proliferation of myofibroblasts. Generally, it is detected in the soft tissue of the extremities, of the trunk and the neck, although involvement of muscles, fasciae and parenchymatous organs was described, and virtually all parts of the body can be affected $[2,3]$. The pathogenesis is currently unknown, although the majority of the authors agree that it consists of a reactive proliferative process triggered by local injury, despite only $10-15 \%$ of them mentioning it $[2,4-6]$. Nodular fasciitis usually affects the young and middle aged individuals, with a balanced male/female ratio, and is rare in the elderly $[3,7]$. The size of the lesions is generally small (i.e., $<3 \mathrm{~cm}$ ); however, sporadically they can be $>10 \mathrm{~cm}[3,8]$.

A few cases of breast nodular fasciitis were described in the scientific literature; the World Health Organization categorized it as one of the benign mesenchymal breast tumors [9-12]. The disease is clinically characterized by sudden onset and rapid growth of a unilateral small and firm nodule, often painless and palpable, resembling a malignant neoplasm. Such clinical manifestations, along with the poor specificity of imaging and cyto-histological features, hinder the differential diagnosis and negatively impacts the therapeutic strategy, which must be as conservative as possible, given the benign nature of the disease and the tendency toward spontaneous regression $[6,8-11]$.

The aim of this article is to describe the clinical, diagnostic, pathological and prognostic features of nodular fasciitis, as well as the therapeutic approach, through a comprehensive review of the cases reported in modern literature.

\section{KARGER}

(c) 2016 S. Karger GmbH, Freiburg

Fax +497614520714
Dr. Panagiotis Paliogiannis Department of Surgical, Microsurgical and Medical Sciences University of Sassari

Viale San Pietro 43, 07100, Sassari, Italy ppaliogiannis@uniss.it 
Table 1. Main demographic and clinical data of patients with breast nodular fasciitis described in modern literature

\begin{tabular}{|c|c|c|c|c|c|c|c|c|}
\hline Author [ref.], year & Sex & $\begin{array}{l}\text { Age, } \\
\text { years }\end{array}$ & $\begin{array}{l}\text { Arousal } \\
\text { time, days }\end{array}$ & $\begin{array}{l}\text { Trauma } \\
\text { history }\end{array}$ & $\begin{array}{l}\text { Breast } \\
\text { cancer } \\
\text { history }\end{array}$ & Side & Quadrant & $\begin{array}{l}\text { Size, } \\
\mathrm{cm}\end{array}$ \\
\hline Törngren et al. [12], 1991 & $\mathrm{~F}$ & 63 & - & - & - & $\mathrm{R}$ & $\mathrm{UO}$ & 1.0 \\
\hline Stanley et al. [8], 1993 & $\mathrm{~F}$ & 42 & 21 & - & - & - & - & 1.5 \\
\hline Birdsall et al. [13], 1995 & $\mathrm{~F}$ & 84 & 35 & - & - & $\mathrm{R}$ & - & - \\
\hline Green et al. [14], 1997 & $\mathrm{~F}$ & 61 & 14 & - & - & $\mathrm{R}$ & $\mathrm{UO}$ & 2.5 \\
\hline Dahlstrom et al. [15], 2001 & $\mathrm{~F}$ & 38 & 10 & No & No & $\mathrm{L}$ & UI & 1.0 \\
\hline Maly and Maly [16], 2001 & $\mathrm{~F}$ & 15 & 21 & - & - & $\mathrm{R}$ & $\mathrm{UO}$ & 2.5 \\
\hline Polat et al. [17], 2002 & $\mathrm{~F}$ & 66 & 60 & - & - & $\mathrm{L}$ & Central & - \\
\hline Tulbah et al. [18], 2003 & $\mathrm{~F}$ & 18 & 42 & - & No & $\mathrm{L}$ & LI & 1.0 \\
\hline Brown and Carty [6], 2005 & $\mathrm{~F}$ & 65 & 30 & - & - & $\mathrm{L}$ & UI & 5.5 \\
\hline Porter et al. [19], 2006 & $\mathrm{~F}$ & 75 & - & - & - & $\mathrm{L}$ & $\mathrm{UO}$ & - \\
\hline$\rightarrow>$ & $\mathrm{F}$ & 52 & - & - & - & $\mathrm{R}$ & Central & - \\
\hline Squillaci et al. [5], 2007 & $\mathrm{M}$ & 40 & 60 & No & - & $\mathrm{L}$ & UI & 4.1 \\
\hline Hayashi et al. [4], 2007 & $\mathrm{~F}$ & 41 & Few & No & No & $\mathrm{R}$ & $\mathrm{UO}$ & 1.0 \\
\hline Ozben et al. [7], 2009 & $\mathrm{~F}$ & 18 & - & No & No & $\mathrm{L}$ & $\mathrm{UO}$ & 0.8 \\
\hline Iwatani et al. [20], 2012 & $\mathrm{~F}$ & 25 & 120 & No & No & $\mathrm{L}$ & LI & 1.2 \\
\hline Son et al. [21], 2013 & $\mathrm{~F}$ & 41 & 7 & No & No & $\mathrm{L}$ & UO-UI & 1.1 \\
\hline Paker [22], 2013 & $\mathrm{M}$ & 17 & 45 & Yes & - & $\mathrm{R}$ & - & 1.5 \\
\hline Samardzic et al. [11], 2014 & $\mathrm{~F}$ & 68 & - & - & No & $\mathrm{R}$ & $\mathrm{UO}$ & 5.6 \\
\hline Rhee et al. [23], 2014 & $\mathrm{~F}$ & 43 & 7 & - & - & $\mathrm{R}$ & UO & 0.6 \\
\hline$->>$ & $\mathrm{F}$ & 32 & 10 & No & - & $\mathrm{L}$ & $\mathrm{UO}$ & 2.0 \\
\hline Yamamoto et al. [24], 2014 & $\mathrm{~F}$ & 35 & - & No & No & $\mathrm{L}$ & $\mathrm{UI}$ & 1.3 \\
\hline Sakuma et al. [25], 2015 & $\mathrm{~F}$ & 31 & - & No & - & $\mathrm{L}$ & $\mathrm{UO}$ & 0.6 \\
\hline
\end{tabular}

$\mathrm{F}=$ Female; $\mathrm{M}=$ male; $\mathrm{R}$ = right $\mathrm{L}=$ left $\mathrm{UO}=$ upper outer; $\mathrm{UI}=$ upper inner; $\mathrm{LI}=$ lower inner.

\section{Materials and Methods}

English-language articles published from January 1990 to October 2015 and related to breast nodular fasciitis were non-systematically retrieved using the PubMed database. The search terms were 'breast fibromatosis', 'breast nodular fasciitis' and 'pseudosarcomatous fasciitis'. Titles and abstracts were evaluated in order to include the most relevant studies. References of the selected articles were cross-checked in order to detect papers missed by the search engine.

\section{Results}

Twenty-two cases included in 20 papers, published in the period under investigation, were analyzed in detail $[4-8,11-25]$. The main demographic and clinical characteristics of the enrolled patients are summarized in table 1.

The majority (20 cases, $91 \%$ ) were women (M/F ratio $10: 1)$, and the mean age was 44 (range 15-84) years. Several clinical, epidemiological and demographic data were partially reported. The mean delay between the arousal of the lesions and clinical examinations, assessed only in 15 patients, was 34 (range 7-120) days. Only 1 out of $10(10 \%)$ reported on a previous trauma. Furthermore, familiar or individual breast cancer history was negative in 8 of $8(100 \%)$ cases. Left and right breasts were affected in $12(57 \%)$ and $9(43 \%)$ cases, respectively; however, the side of the lesion was not mentioned in 1 case. The mean diameter of the lesions, computed during the pathological or the ultrasound (US) examination, was 1.9 (range $0.6-5.6) \mathrm{cm}$ in 18 patients.
Table 2. Imaging techniques employed for diagnosis in 18 cases of nodular fasciitis

\begin{tabular}{lc}
\hline Technique & $\mathrm{n}(\%)$ \\
\hline US & $16(89)$ \\
Mammography & $16(89)$ \\
MRI & $4(22)$ \\
CT & $1(6)$ \\
\hline
\end{tabular}

After clinical examination, the borders of the lesions were 'welldefined' in 7 of 8 (87.5\%) cases, whereas their consistency resulted 'firm' or 'hard' in 8 of 10 (80\%), soft-to-hard in $1(10 \%)$ and soft in $1(10 \%)$. Lesions were considered mobile in 5 of $6(83 \%)$, without any skin retractions and areola alterations, respectively, in 7 and 5 cases where information was reported. No axillary lymph node swelling was observed in 9 cases. Painless lesions were described in 11 of $13(85 \%)$ cases.

Table 2 summarizes the imaging techniques adopted during the diagnostic process. The most frequently employed ( 90\%) were US and mammography, followed by MRI and CT. In 13 (59\%) cases, both US and mammography were used.

The mammographic features of the lesions were described in some of the cases reviewed. Density patterns were variable from dense in 5 of $11(45 \%)$ to isodense in 2 of $11(18 \%)$, with a focal asymmetry in 2 of $11(18 \%)$, opaque in 1 of 11 (9\%) and soft tissuelike density in 1 of 11 (9\%) cases; the shape of the lesions was described as irregular in 3 of 9 (33\%), spiculated or stellate in 3 of 9 (33\%), oval in 1 of $9(11 \%)$, regular in 1 of $9(11 \%)$ and round in 1 
Table 3. Employment and results of FNA and $\mathrm{CB}$ in the cohort reviewed

\begin{tabular}{lc}
\hline & $\mathrm{n}(\%)$ \\
\hline Method & \\
FNA & $9(41)$ \\
CB & $4(18)$ \\
FNA + CB & $3(14)$ \\
Not performed & $4(18)$ \\
Not available & $2(9)$ \\
Results (in 16 cases) & \\
Diagnosis obtained & $4(25)$ \\
Nodular fasciitis suspected & $2(12.5)$ \\
Inconclusive & $10(62.5)$ \\
\hline
\end{tabular}

of $9(11 \%)$ cases. No calcifications were reported in 4 of 4 (100\%) cases, and margins were poorly defined in 7 of $9(77 \%)$, irregular in 1 of $9(11 \%)$ and well-defined in $1 / 9(11 \%)$ cases.

Hypoechoic features were described in all the $11(100 \%)$ cases in which information about the US characteristics of the nodules was provided; a hyperechoic halo was observed in 6 of 11 (54\%) cases, whereas perilesional invasion only in 1 of $4(25 \%)$ case. The margins of the lesions were irregular in 8 of $9(88 \%)$ cases. Vascularity evidenced by Doppler US was described only in 2 cases, and it was absent and minimal, respectively. Acoustic shadow was detected in 3 of $5(60 \%)$, and acoustic enhancement in 1 of $3(33 \%)$ cases.

MRI was performed only in 4 cases: it was negative in 1 patient following a spontaneous regression of the nodule, while in 2 other cases intense enhancement in T1-weighted imaging was reported. In 1 case described by Rhee et al. [23], the lesion was hypointense in T1- and hyperintense in T2-weighted imaging, with a rapid and persistent enhancement. CT scan was carried out in 1 case, where chest wall invasion was suspected.

Fine needle aspiration (FNA) and/or core biopsy (CB) were frequently (16 cases, $72 \%$ ) employed for diagnosis (table 3 ), but their diagnostic accuracy was poor with a definitive diagnosis obtained only in $25 \%$ of the cases. The most frequently used was FNA (12 cases, 55\%); in 3 (14\%) cases, both FNA and CB were employed. The typical FNA pattern showed isolated spindle-shaped cells mixed with tissue fragments, mimicking other neoplastic and nonneoplastic breast conditions, such as fibromatosis, myofibroblastoma, inflammatory myofibroblastic tumor, benign fibrous histiocytoma, spindle cell lipoma, phyllodes tumor, metaplastic carcinoma, and sarcoma $[22,26,27]$. A surgical excision was often required to obtain the final diagnosis.

The pathological gross examination was detailed in a few cases: the color was white or whitish in 5 of 7 (71\%), and grayish in 2 of 7 (29\%) lesions; whereas the borders were well-defined in 2 of 3 (67\%) and stellate in 1 of $3(33 \%)$ lesions; and the consistency firm, hard or solid in 7 of 7 (100\%) lesions. Only 1 of $3(33 \%)$ lesion was partially capsulated. Histopathologically, fibroblasts were arranged in bundles or fascicles in 10 of 13 (77\%), while packed and disorganized or scattered in 2 of 13 (15\%) cases and formed nodularities in 1 of $3(7 \%)$ cases. Cellularity was described as variable, moderate and loose in 5 of 8 (71\%), 2 of $8(29 \%)$ and 1 of $8(14 \%)$ cases, re-
Table 4. Immunohistochemistry in nodular fasciitis

\begin{tabular}{lll}
\hline Marker & Cases, $\mathrm{n}$ & Result \\
\hline SMA & 7 & Positive in all cases \\
CD 34 & 6 & Negative in 4, positive in 2 \\
Desmin & 4 & Negative in 3, positive in 1 \\
S-100 & 4 & Negative in all cases \\
CD 68 & 4 & Positive in 3, negative in 1 \\
Vimentin & 2 & Positive in all cases \\
AE1/AE3 & 2 & Negative in all cases \\
Cytocheratin & 2 & Negative in all cases \\
HMWK & 1 & Negative \\
Beta-catenin & 1 & Negative \\
MSA & 1 & Negative \\
Factor XIIIa & 1 & Positive \\
ALK & 1 & Negative \\
\hline
\end{tabular}

HMWK = High molecular weight keratin; MSA = muscle specific actin; ALK = anaplastic lymphoma kinase.

spectively, and the shape as spindle or stellate-spindle in 13 of 13 (100\%) cases. Furthermore, mitotic activity was reported as rare, occasional or scanty in 7 of $9(77 \%)$ cases, and numerous normal in 2 of $9(23 \%)$ cases. The margins of the lesions were irregular in 9 of 10 (90\%). Perilesional infiltration or entrapment of the adjacent tissue was reported in 9 of 9 cases. Stroma appeared as myxoid in 8 of $12(67 \%)$, collagenous/myxoid in 3 of $12(25 \%)$ and myxoid/ fibrotic in 1 of 12 (8\%); hyalinization and extravasation were reported in $3(13.5 \%)$ and 9 (41\%) cases, respectively. The most commonly employed immunohistochemical markers are smooth muscle actin (SMA), CD 34, desmin, S-100 and CD 68. SMA and CD 68 are generally positive, while the others are negative. Positive vimentin and negative AE1/AE3 were also reported (table 4).

The treatment option adopted is reported in 20 cases. An excisional biopsy was performed in 14 of 20 (70\%) patients, while a 'wait and see' approach was adopted in 4 of 20 (20\%) individuals in which spontaneous resolution was observed. A vacuum-assisted removal (5\%) and a modified radical mastectomy in a patient with a chronic respiratory insufficiency and a small breast (5\%) were performed in the remaining 2 cases. The mean follow-up was 11 (range 1-24) months for 7 patients. No recurrences, disseminations or deaths were reported. In cases of spontaneous resolution, the time lag between the diagnosis and the confirmed resolution ranges from 1 month to 2 years.

\section{Discussion}

Breast nodular fasciitis is an extremely rare clinical condition, with only a few cases reported in the medical literature [24]. Its rarity and unspecific clinical and radiological characteristics make the differential diagnosis and the management challenging. It mainly affects middle aged women, with an age distribution similar to that described for fasciitis of other anatomical districts, in which the percentage of male patients is consistently higher (up to 50\%) [3]. 
The report of a traumatic event preceding the occurrence of the disease is rare, being described only in $15 \%$ of the cases involving all the anatomical districts of the human body [2, 4, 5]; our case series showed that the percentage can be lower (10\%) in individuals with a breast lesion. Furthermore, a history of previous or familiar breast cancers does not seem to influence the probability of the disease.

The clinical progression of the nodules seems rapid. Bernstein et al. [3] in their series of 134 clinical cases report that 13 successfully treated patients were managed within 1 week from the first symptoms and signs and 39 within 1 month. This pattern is similar to that observed in our review. Such a rapid growth and evolution is not common in other breast nodules, especially the malignant ones, and may indicate or even be pathognomonic of nodular fasciitis.

The UO quadrants of the breasts are most frequently affected, similar to the most common malignant breast cancers [28]. The lesions are generally painless, even if pain may be present in some cases. The mean size of the lesions is approximately $2 \mathrm{~cm}$, although nodules as small as $0.6 \mathrm{~cm}$ or greater than $6 \mathrm{~cm}$ have been described [8]. During palpation, nodules appeared to be well-defined, firm or hard and mobile; however, in a few cases, they can be soft and fixed in the surrounding tissues. Also, skin retraction or involvement of the nipple-areola complex is rare, although possible; the axillary lymph nodes are never involved as opposed to malignant tumors $[29,30]$.

Mammography and US represent the most commonly employed methods for the anatomical assessment of nodular fasciitis. Some cases in which a surgical excision was provided without a preoperative mammographic or ultrasonographic evaluation were reported; Tulbah et al. [18] performed a surgical excision of a nodule diagnosed as a fibroadenoma without such evaluations. MRI and CT scan do not add consistent diagnostic information, and may be helpful in cases of soft tissue invasion, rather than as a routine evaluation.

The most common mammographic appearance of breast fasciitis is that of a dense, irregular or spiculated nodule, with poorly defined margins. It can also be regular, oval or round with welldefined margins in some cases. Calcifications are usually not detected. On US, the lesions are constantly hypoechoic, but can show hyperechoic halo, acoustic shadow or enhancement. The margins are often irregular, and perilesional invasion of the breast or fatty tissue can be detected. Vascularity is generally minimal or completely absent.

Breast nodular fasciitis may resemble several other breast lesions, which may present similar radiological or even pathological features, such as fibromatosis, myofibroblastoma, inflammatory myofibroblastic tumor, benign fibrous histiocytoma, spindle cell lipoma, phyllodes tumor, metaplastic carcinoma and sarcoma, as we have mentioned before. Differential diagnosis is essential, especially with potentially aggressive lesions like phyllodes tumors, metaplastic carcinoma and sarcoma. The former is commonly biphasic and shows large cohesive epithelial fragments and numerous naked nuclei in addition to the spindle-shaped mesenchymal cells [22]. Metaplastic carcinoma commonly consists of a population of spindle cells disposed individually or in cell groups in a myxoid context; the lesions, as opposed to nodular fasciitis, show immunohistochemical cytokeratin positivity $[22,26]$. Primary sarcomas of the breast may also present spindle cells, but the nuclear features and the clinical findings are enough for the correct differential diagnosis [22]. Excisional biopsy represents the most commonly used procedure, both for diagnostic and therapeutic purposes. More relevant surgical operations are sporadically described, as in the case of Törngren et al. [12] who performed a modified radical mastectomy in a patient with chronic respiratory insufficiency and a very small breast. Similar approaches have been described in older articles [31]. Another less invasive option is the US-guided vacuum assisted excision used by Rhee et al. [23]. Finally, a 'wait and see' approach was successfully adopted in some cases where autonomous resolution was observed. Spontaneous resolution is also reported in series including other than breast lesions [8]. It seems that resolution does not depend on the size of the lesion; Brown and Carty [6] described a $5.5 \mathrm{~cm}$ lesion spontaneously and rapidly regressed. Nevertheless, it is difficult to establish the appropriate criteria for a correct decision between excisional biopsy and conservative management. A non-operative approach should be considered in typical cases with clinical, imaging and biopsy features, as those described before $[6,24]$. If the criteria for such an approach are not met, US-guided vacuum or surgical excision should be provided to establish definitive diagnosis and to cure. Recurrences after surgery for nodular fasciitis have been described [3]. Nevertheless, no recurrences were observed in the breast cases we reviewed, and all patients in whom follow-up information was available remained free of disease. Therefore, recurrence seems to be an exceptional event, although more data on the excisional procedures used and the healthy tissue margins obtained are necessary to better assess this issue. In all cases, the prognosis of nodular fasciitis of the breast is good.

\section{Conclusions}

Breast nodular fasciitis is a rare, benign condition commonly affecting middle aged women and frequently confounded with other neoplastic and non-neoplastic disorders. This can lead to relevant difficulties in the management of the disease, particularly to overtreatment. Knowledge of its typical demographic, clinical and pathological aspects is crucial for breast care specialists in order to improve their diagnostic and therapeutic interventions.

\section{Disclosure Statement}

The authors declare no conflicts of interest. 


\section{References}

1 Konwaler BE, Keasbey L, Kaplan L: Subcutaneous pseudosarcomatous fibromatosis (fasciitis). Am J Clin Pathol 1955;25:241-252.

2 Hutter RV, Stewart FW, Foote FW Jr: Fasciitis. A report of 70 cases with follow-up proving the benignity of the lesion. Cancer 1962;15:992-1003.

3 Bernstein KE, Lattes R: Nodular (pseudosarcomatous) fasciitis, a nonrecurrent lesion: clinicopathologic study of 134 cases. Cancer 1982;49:1668-1678.

4 Hayashi H, Nishikawa M, Watanabe R, Sawaki M, Kobayashi H, Shibata A, Kikumori T, Nagasaka T, Imai T: Nodular fasciitis of the breast. Breast Cancer 2007;14:337-339.

5 Squillaci S, Tallarigo F, Patarino R, Bisceglia M: Nodular fasciitis of the male breast: a case report. Int J Surg Pathol 2007;15:69-72.

6 Brown V, Carty NJ: A case of nodular fascitis of the breast and review of the literature. Breast 2005;14: 384-387.

7 Ozben V, Aydogan F, Karaca FC, Ilvan S, Uras C: Nodular fasciitis of the breast previously misdiagnosed as breast carcinoma. Breast Care (Basel) 2009;4:401402.

8 Stanley MW, Skoog L, Tani EM, Horwitz CA: Nodular fasciitis: spontaneous resolution following diagnosis by fine-needle aspiration. Diagn Cytopathol 1993;9:322324

9 Rosen PP, Ernsberger D: Mammary fibromatosis. A benign spindle-cell tumor with significant risk for local recurrence. Cancer 1989;63:1363-1369.

10 Wargotz ES, Norris HJ, Austin RM, Enzinger FM: Fibromatosis of the breast. A clinical and pathological study of 28 cases. Am J Surg Pathol 1987;11:38-45.

11 Samardzic D, Chetlen A, Malysz J: Nodular fasciitis in the axillary tail of the breast. J Radiol Case Rep 2014;8: $16-26$.
Törngren S, Frisell J, Nilsson R, Wiege M: Nodular fasciitis and fibromatosis of the female breast simulating breast cancer. Case reports. Eur J Surg 1991;157:155158

13 Birdsall SH, Shipley JM, Summersgill BM, Black AJ, Jackson P, Kissin MW, Gusterson BA: Cytogenetic findings in a case of nodular fasciitis of the breast. Cancer Genet Cytogenet 1995;81:166-168.

14 Green JS, Crozier AE, Walker RA: Case report: nodular fasciitis of the breast. Clin Radiol 1997;52:961-962.

15 Dahlstrom J, Buckingham J, Bell S, Jain S: Nodular fasciitis of the breast simulating breast cancer on imaging. Australas Radiol 2001;45:67-70.

16 Maly B, Maly A: Nodular fasciitis of the breast: report of a case initially diagnosed by fine needle aspiration cytology. Acta Cytol 2001;45:794-796.

17 Polat P, Kantarci M, Alper F, Gursan N, Suma S, Okur A: Nodular fasciitis of the breast and knee in the same patient. AJR Am J Roentgenol 2002;178:1426-1428.

18 Tulbah A, Baslaim M, Sorbris R, Al-Malik O, Al-Dayel F: Nodular fasciitis of the breast: a case report. Breast J 2003;9:223-225.

19 Porter GJ, Evans AJ, Lee AH, Hamilton LJ, James JJ: Unusual benign breast lesions. Clin Radiol 2006;61: 562-569.

20 Iwatani T, Kawabata H, Miura D, Inoshita N, Ohta Y: Nodular fasciitis of the breast. Breast Cancer 2012;19: 180-182.

21 Son YM, Nahm JH, Moon HJ, Kim MJ, Kim EK: Imaging findings for malignancy-mimicking nodular fasciitis of the breast and a review of previous imaging studies. Acta Radiol Short Rep 2013;2:2047981613512830.

22 Paker I, Kokenek TD, Kacar A, Ceyhan K, Alper M: Fine needle aspiration cytology of nodular fasciitis presenting as a mass in the male breast: report of an unusual case. Cytopathology 2013;24:201-203.
3 Rhee SJ, Ryu JK, Kim JH, Lim SJ: Nodular fasciitis of the breast: two cases with a review of imaging findings. Clin Imaging 2014;38:730-733.

24 Yamamoto S, Chishima T, Adachi S: Nodular fasciitis of the breast mimicking breast cancer. Case Rep Surg 2014;2014:747951.

25 Sakuma T, Matsuo K, Koike S, Tagami K: Fine needle aspiration cytology of nodular fasciitis of the breast. Diagn Cytopathol 2015;43:222-229.

26 Nonnis R, Paliogiannis P, Giangrande D, Marras V, Trignano M: Low-grade fibromatosis-like spindle cell metaplastic carcinoma of the breast: a case report and literature review. Clin Breast Cancer 2012;12:147-150.

27 Odashiro AN, Odashiro Miiji LN, Odashiro DN, Nguyen GK: Mammary myofibroblastoma: report of two cases with fine-needle aspiration cytology and review of the cytology literature. Diagn Cytopathol 2004; 30:406-410.

28 Cossu A, Paliogiannis P, Attene F, Palmieri G, Budroni M, Sechi O, Torre C, Tanda F, Scognamillo F: Breast cancer incidence and mortality in north sardinia in the period 1992-2010. Acta Med Mediterr 2013;29:235-239.

29 Attene F, Paliogiannis P, Scognamillo F, Trignano E, Pala C, Trignano M: Axillary lymph node dissection in patients with breast cancer and sentinel lymph node micrometastasis or isolated tumor cells: is it necessary? Tumori 2012;98:320-325

30 Recht A, Houlihan MJ: Axillary lymph nodes and breast cancer: a review. Cancer 1995;76:1491-1512.

31 Baba N, Izuo $M$, Ishida $T$, et al: Pseudosarcomatous fasciitis of the breast simulating a malignant neoplasm: a case report and ultrastructural study. Jpn J Clin Oncol 1978;8:169-180. 